of the project, its rationale, and its interfaces with com plementary initiatives and organisations.

This volume represents the culmination of that undertaking. The introductory overview gives a detailed account of the role and interest of IUPAC in promoting this initiative and provides an account of the historical emergence of the concept. This is followed by a synoptic preamble, in which the content and purpose of individual reviews in the issue are summarized. The Symposium-in-Print captures the current status of the discipline and projects the boundless opportunities and challenges confronting contemporary organic synthesis and its practice in a changing world, increasingly sensitized to the finite bounds of natural resources and the vulnerability of the biosphere. The issue offers evidence that current problems are being addressed and can be solved, and engenders expectations that future problems can be anticipated and prevented.

www.iupac.org/publications/pac/2000/
7207/japanese_title.html
www.iupac.org/publications/pac/2000/
7207/index.html

\section{Polymer Characterization and Materials Science}

R. D. Sanderson and H. Pasch Macromolecular Symposia, Vol. 178.

Wiley-VCH, 2002, pp. 1-181.

(ISBN 3-527-30468-1)

This volume contains selected papers presented at the UNESCO School and IUPAC Conference on Macromolecules and Materials Science, held in Stellenbosh, South Africa, in April 2001. World authorities in various fields of macromolecular science were invited to give tutorials at the UNESCO School and informative plenaries at the conference. The exposure to new ideas and advanced concepts in macromolecular science is of great importance for South African students and senior staff alike. It is particularly valuable that with the support of UNESCO, generous concessions can be made for attendees from disadvantaged communities and from countries with emerging technologies.

The $4^{\text {th }}$ UNESCO School and IUPAC Conference focused on polymer characterization, new polymer architectures and nanomaterials. Abridged versions of a number of papers are compiled to create the present volume of Macromolecular Symposia. The content of the papers is also available in the Virtual Teaching Encyclopaedia which contains papers from previous UNESCO conferences as well <www.sun.ac.za/unesco/unesco.htm〉.

www.iupac.org/publications/macro/2002/ 178_preface.html
Non-Metals in Liquid Alkali Metals

Hans Ulrich Borgstedt and Cezary Guminski

IUPAC-NIST Solubility Data Series. 75.

Journal of Physical and Chemical Reference Data, Vol. 30, No. 4, pp. 835-1158, 2001.

All available solubility data of nonmetallic elements and some of their compounds in the five liquid alkali metal solvents ( $\mathrm{Li}, \mathrm{Na}, \mathrm{K}, \mathrm{Rb}$, and $\mathrm{Cs}$ ) are collected and com piled. Original publications with reliable data and information on the methods used to generate them are reported in individual compilations. When numerical data are not given in a publication, the data are often read out from figures and converted into numerical data by the compilers. The precision of this procedure is indicated in the compilations under estimated error. Evaluated solubility data are tabulated at the end of the critical evaluations: if there is agreement of at least two independent studies within the experimental error, the solubility values are assigned to the "recommended" category. Values are assigned as "tentative" if only one reliable result was reported, or if the mean value of two or more reliable studies was outside the error limits. In the tabulation, three, two, or one significant figures are assigned for respective precisions that are better than $\pm 1 \%$ and $\pm 10 \%$ and worse than $\pm 10 \%$. If necessary, the solubilities are recalculated into mol $\%$.

The completeness of this investigation of the literature has been confirmed and extended by studying several reviews dealing with the solution chemistry of substances in the alkali metals. Solubility data are sometimes measured under parameters, which are not standard conditions of such measurements. Frequently measurements are performed under constrained pressure. The solubility of noble gases or other gases, which do not form compounds with the alkali metals, depends on the gas pressures. This dependency is documented in the data sheets.

\begin{tabular}{|c|c|}
\hline www.iupac.org/publications/sds/ & 2001/75_abstract.html \\
www.iupac.org/projects/2001/2001-034-1-500.html \\
wwitis
\end{tabular}

Heat Capacity of Liquids: Critical Review and Recommended Values

Milan Zábranský, Vlastimil Ruzicka, Jr., and Eugene S. Domalski

Journal of Physical and Chemical Reference Data, 30, No. 5, pp. 1199-1689, 2001.

A study was carried out in which new experimental data on heat capacities of pure liquid organic and some inorganic compounds were compiled and critically evaluated. The study also provided recommended values. Compounds included in the compilation have a melting point below $573 \mathrm{~K}$. The bulk of the compiled data cover 